\title{
Implementation of an early warning system in urban drainage infrastructures for direct discharges and flood risk management
}

\author{
R. Matos ${ }^{1}$, F. Ferreira ${ }^{1}$, J. Saldanha Matos ${ }^{1}$, A. Oliveira ${ }^{2}$, \\ L. David ${ }^{2}$, M. Rodrigues ${ }^{2}$, G. Jesus ${ }^{2}$, J. Rogeiro ${ }^{2}$, J. Costa ${ }^{2}$,

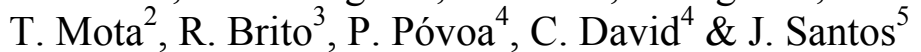 \\ ${ }^{1}$ IST/UTL, Portugal \\ ${ }^{2}$ LNEC, Portugal \\ ${ }^{3}$ ESTBarreiro/IPS, Portugal \\ ${ }^{4}$ SimTejo S.A., Portugal \\ ${ }^{5}$ Siemens, S.A., Portugal
}

\begin{abstract}
Combined sewer systems are often unable to respond adequately to rising water volumes draining from urban areas during rainfall events, resulting in frequent direct discharges into receiving waters and floods, with severe environmental and economic impacts. Despite stricter legislation on pollution control and flood risk assessment, there are still some challenges regarding the development of early warning systems based on water quality issues and fully integrated models. An innovative, real-time urban warning system for flooding and pollution events was built for the Alcântara basin (the largest in Lisbon), to provide timely information to wastewater management entities and to civil protection services. The platform provides real-time access to monitoring data and, based on 48-hour precipitation forecasts, predicts the performance of the system through the integrated use of mathematical models for both drainage network and estuary. Predictions are automatically compared and validated with on-line data. This paper presents the overall design of the system and main results obtained thus far. The analysis of the system shows the ability of the integrated models to represent the main spatial and temporal patterns observed, effectively predicting the system response to precipitation events and estimating volumes discharged into the water bodies and their average pollution loads. Furthermore, the overall
\end{abstract}


results strongly indicate $\mathrm{UV}-\mathrm{Vis}$ spectra to be reliable for TSS and COD estimation in sewer systems.

Keywords: early warning systems, integrated modelling, UV-Vis, real time monitoring, wastewater systems, urban floods.

\section{Introduction}

The increase of urban impervious areas, resulting in rising stormwater volumes and peak flows (Goonetilleke et al. [1]), coupled with rainfall events with expectedly increasing intensities and frequency, often lead to an insufficient response by combined sewer systems. As a consequence, direct discharges into receiving waters and in surface water floods occur some of which may have negative environmental and economic impacts.

Stricter legislation on discharge pollution control and flood risk assessment (EU Directives 2000/60/EC, 2007/60/EC and 2006/7/EC), and the increasing awareness of authorities and the public, have contributed to the significant development of early warning systems (EWS) over the last decades. EWS development, especially regarding urban flood events and discharge effects on estuarine hydrodynamics has already been largely reported (Fotopoulos et al. [2], Falconer et al. [3], Borga et al. [4], Alfieri et al. [5], Parker et al. [6], David et al. [7]). Nevertheless, current EWS still face some challenges regarding data accuracy and real time availability, and the inclusion of water quality in the forecasting processes, towards effectively contributing to anticipate potential pollution events and mitigate their impacts. Multi-wavelength spectroscopy in the ultraviolet visible range (UV-Vis) has already been used for wastewater and stormwater quality monitoring. However, variable hydraulic conditions, fouling, heterogeneous wastewater composition and limited maintenance may create a challenge for its continuous real time use (Salgado Brito et al. [8]).

Timely prediction of potential flooding or pollution discharges requires integrated models of the behavior of all systems components (drainage network, wastewater treatment plants and receiving waters). In this context, an innovative, real-time urban early-warning system was built for the Alcântara basin (the largest in Lisbon, operated by SIMTEJO, S.A.), to provide timely information to wastewater management entities and to civil protection services. This platform provides real-time access to monitoring data and, based on 48-hour precipitation forecasts, predicts the performance of the system through the integrated use of mathematical models for all relevant domains: drainage network and estuary. Predictions are automatically compared and validated with on-line data, providing a continuous, independent assessment of the system's reliability.

\section{Case study: the Alcântara basin in Lisbon}

The city of Lisbon is situated on a waterfront and is served by an extensive drainage network composed mostly of combined sewer systems. The Alcântara subsystem covers an area of 6200 ha and includes approximately $25 \mathrm{~km}$ of interceptors, eleven pumping stations and a wastewater treatment plant (WWTP). 
The WWTP has a treatment design capacity of 600000 equivalent inhabitants. The dry-weather treatment capacity is of $3.3 \mathrm{~m}^{3} / \mathrm{s}$ (using Multiflo ${ }^{\circledR}$ process for primary treatment and biofiltration, Biostyr ${ }^{\circledR}$, for biological treatment) and an additional $3.3 \mathrm{~m}^{3} / \mathrm{s}$ capacity is available for wet-weather flow (using advanced physicochemical treatment, Actiflo ${ }^{\circledR}$ process). During dry weather roughly $60 \%$ of inflows reach the WWTP by gravity, while the remaining inflow is pumped through an interceptor system (Figure 1).
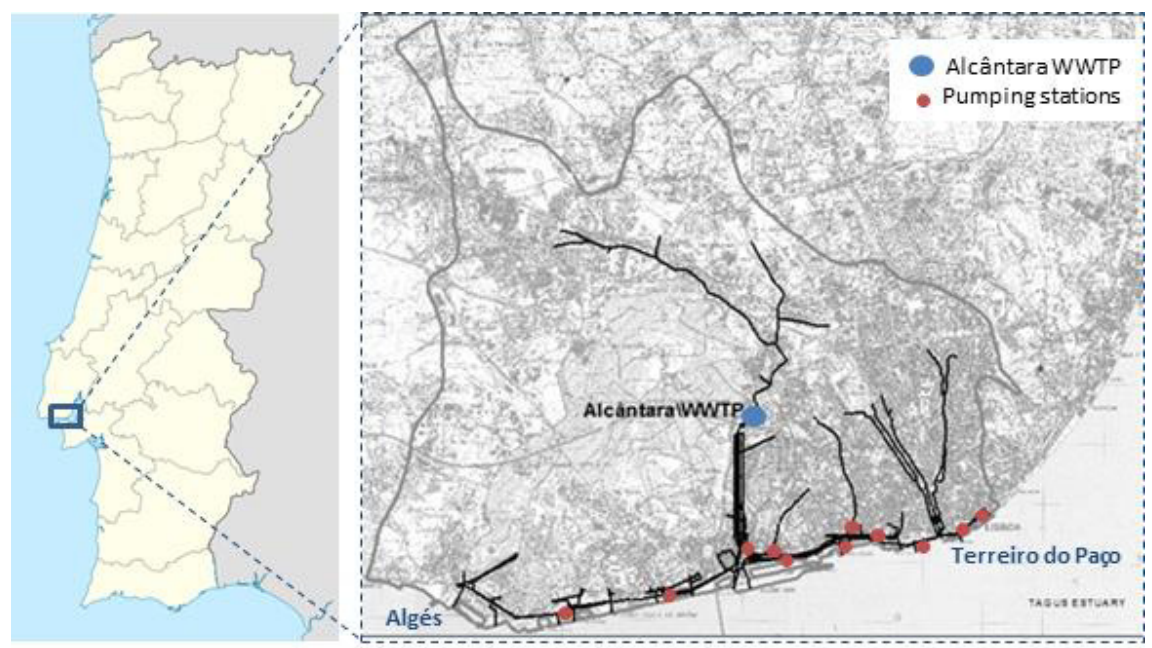

Figure 1: Alcântara basin in Lisbon.

Due to a combination of site specific factors, namely the existence of low slopes, tidal intrusion and sediment deposition, the city's downtown area is often subjected to flooding when intense precipitation occurs. During these periods, direct effluent discharges also occur as a result of combined sewer overflows (CSO).

\section{Material and methods}

\subsection{General description of the early warning system}

The early warning system is based on a flux of information between the different models and forcing predictions (Figure 2), supervised by real time monitoring flow meters, rain gauges and water quality equipment located on strategic sections of the sewer network, the WWTP and the estuary.

The modelled sewer system can be divided into four main branches, namely the Caneiro upstream and downstream gravity sewer models, the Algés Alcântara riverfront model, located west of the WWTP, and the Terreiro do Paço - Alcântara riverfront model, located east of the WWTP. Flow simulation on the sewer system is forced by forecasts from the atmospheric model, which in turn 
will result as inflow to the WWTP and CSO discharges to the estuary. Treated outflow from the WWTP is then introduced as inflow to the downstream Caneiro gravity sewer, prior to its discharge into the estuary. The WWTP treated effluent and the CSO discharges are the urban catchment forcing variables to the estuary model. Additionally, for the estuary model, atmospheric predictions, Tagus river flow and ocean conditions are also considered at the remaining boundaries.

Estuary water levels are used to force the tidal influence on the discharge points from the sewer system.

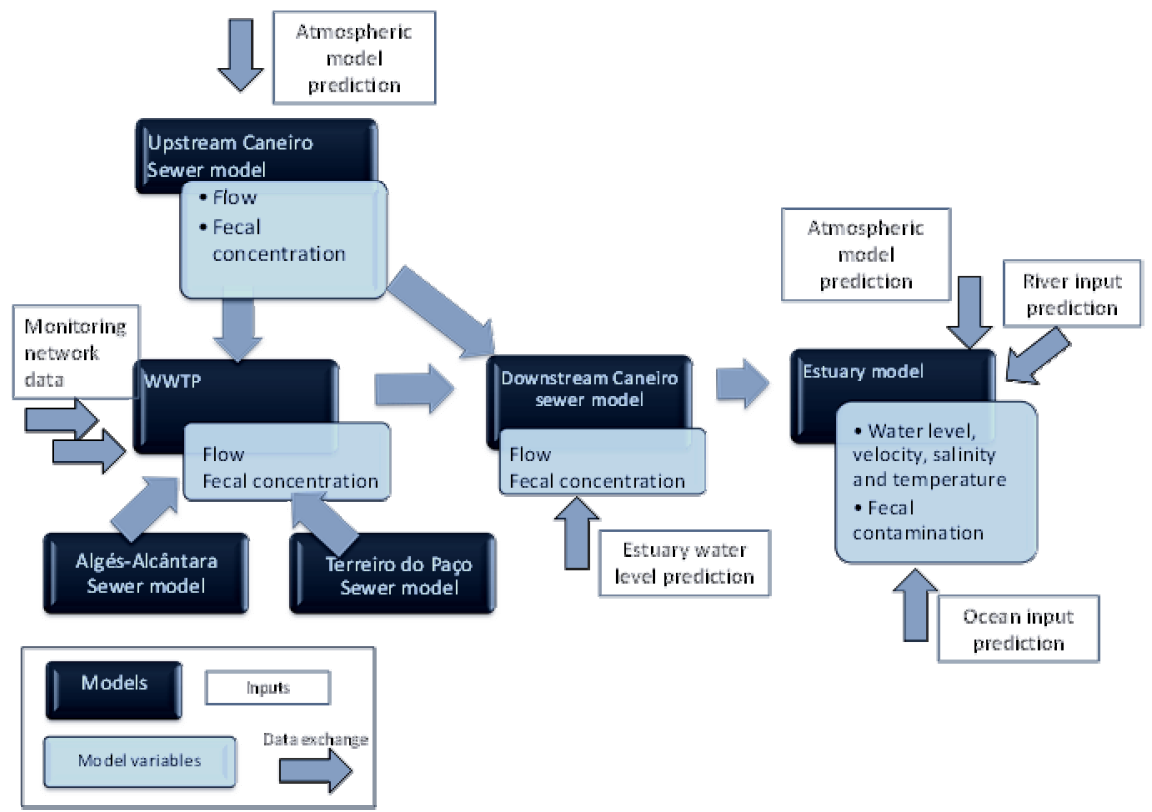

Figure 2: $\quad$ Schematic flux of data between model components at the Alcântara urban sewer system.

\subsection{Numerical modelling}

The numerical simulation of the sewer network is performed using SWMM 5 (Rossman [9]). The higher and lower sections of the network system, as well as the WWTP were first modelled individually and then integrated into one single model. This combined model is capable of providing information on water quantity and quality discharged into the estuary (Figure 3). Sediment deposition in lower areas of the city is taken into account by using the procedure proposed by (Ashley et al. [12]), where different percentages of sediments result in specific roughness coefficients applied to sewers. The model was calibrated using a deterministic approach and considering the monitoring data consistently collected in the past, for large time periods (over one year). Later the model was verified for several dry and wet weather events. 
The hydraulics of the WWTP is also modelled using SWWM throughout the different components of the treatment plant. A semi-empirical model for quality parameters (Total Suspended Solids, Chemical Oxygen Demand and Faecal coliforms) for dry and wet weather was developed. The semi-empirical model allows modelling wastewater quality along the WWTP components. This model takes into account the past monitoring data regularly collected in the WWTP, as well as experimental data gathered at several locations during the experimental campaigns.

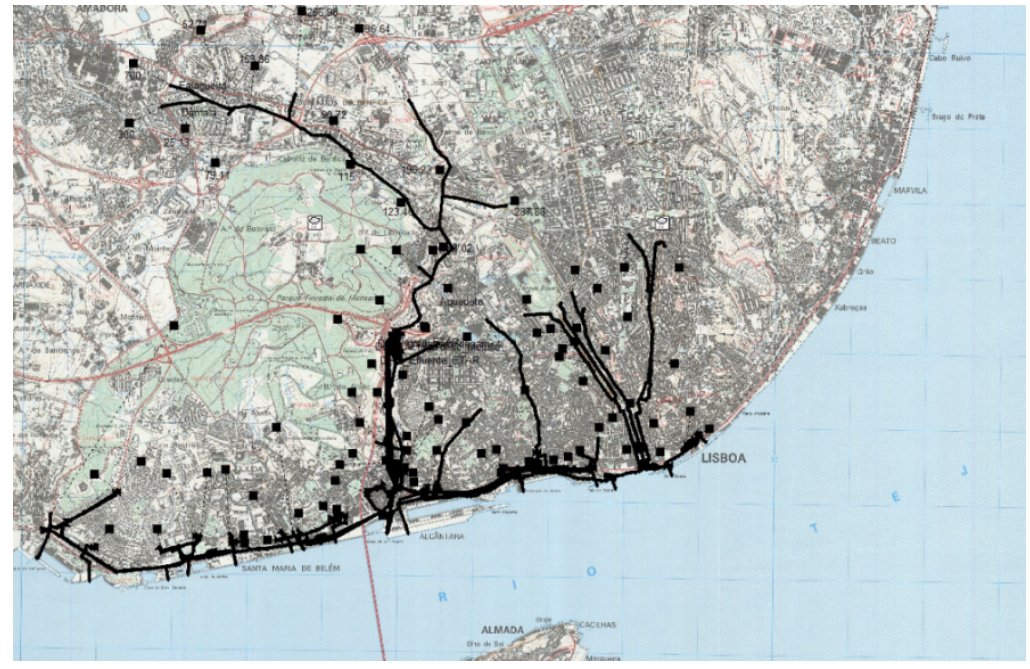

Figure 3: Sewer network and WWTP integrated model (SWMM) for the Alcântara basin.

Receiving waters (Tagus estuary) hydrodynamics and faecal contamination are modelled using the 3D unstructured grid model ECO-SELFE $3.1 \mathrm{~d}$ (Rodrigues et al. [10]), setting the Atlantic Ocean as a downstream boundary. Upstream boundaries include the Tagus river inflow as well as the discharge from the WWTP and six other discharge points located on the riverfront.

\subsection{Data monitoring}

Data monitoring in the Alcântara basin is carried out by several flow meters (30 installed throughout the sewage network system and 6 in the WWTP). In addition, real time data on precipitation and on UV-Vis spectra was collected. Four rain gauges were located in the basin and three UV-Vis spectrophotometers were available, two installed in the WWTP and a third one in the estuary, near the main Alcântara outfall.

A level meter was installed in the downtown area at a specific location known by the wastewater management entity as historically subjected to urban flooding when intense precipitation occurs. 


\subsection{UV-Vis spectroscopy to estimate quality parameters}

The EWS under development is based on in-line UV-Vis spectroscopy to estimate quality parameters. A detailed study was formerly carried out in order to assess UV-Vis spectroscopy applicability to evaluate Total Suspended Solids (TSS) and Chemical Oxygen Demand (COD). In such study, nine campaigns were performed, in different weather conditions, at two different locations of the sewer network, which lasted from 3 to 7 hours. Standard TSS and COD laboratory analyses of collected samples were done and in-line and off-line UVVis spectra were acquired. Three models were developed and statistically evaluated for Partial Least Squares calibration (PLS), namely: A) PLS model based on UV-Vis spectra acquired offline; B) PLS model based on UV-Vis spectra acquired in-line and C) model included in the submersible probe software (Spectro::lyser S::can). Detailed information on the methodology used can be found in Brito .

\subsection{Experimental campaigns}

In order to improve model validation and integration, a set of field surveys was planned to synoptically characterize hydraulic and water quality parameters from the sewer and the estuary. Four water quality stations were selected in the sewer system and three in the estuary (Figure 4). Three dry weather and two wet weather experimental campaign were carried out for 13 hour periods to allow the characterization of a complete tidal cycle (8:30 to 21:30) and the following parameters were measured (using probes and laboratory analysis): temperature, $\mathrm{pH}$, conductivity, turbidity, salinity, dissolved oxygen, total suspended solids, chemical oxygen demand, biochemical oxygen demand, phosphates, faecal coliforms, E. coli and ammonia.

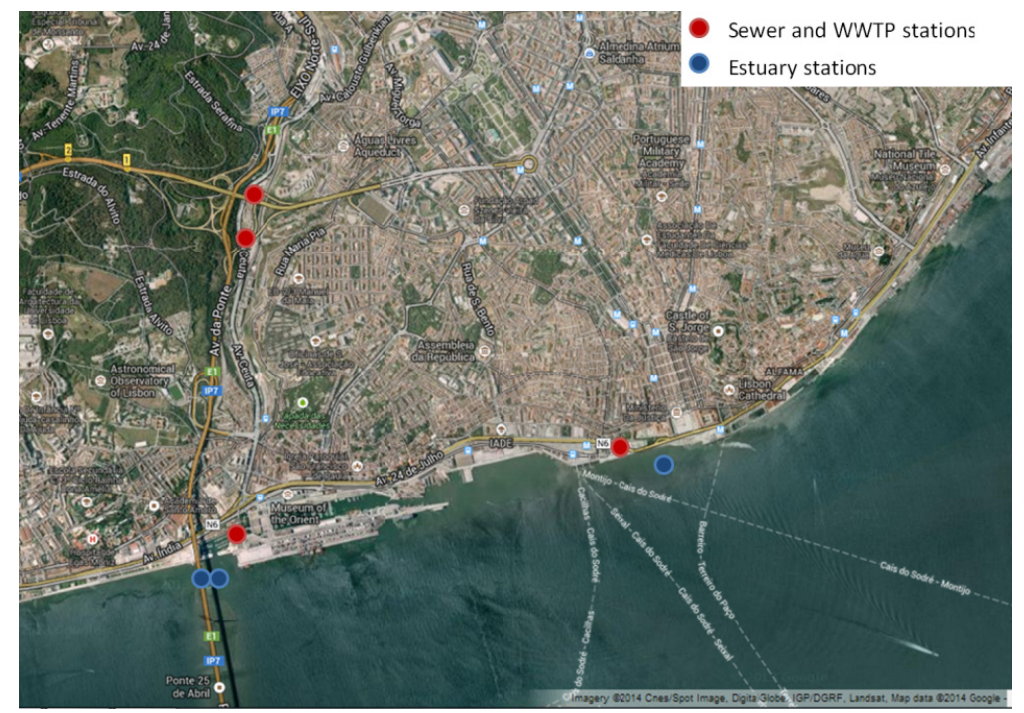

Figure 4: Quality monitoring stations. 


\subsection{Real time prediction and modelling}

Real time predictions are based on the RDFS-PT system (Jesus et al. [11]) extended for coupled sewer and estuary modelling (David et al. [7]) and upgraded to include microbiological contamination in the estuary $(E$. coli and faecal coliforms). Atmospheric forecasts use the WRF $9 \mathrm{~km}$ model (http://www.windguru.cz) and the GFS $50 \mathrm{~km}$ model (http://nomads.ncep .noaa.gov/).

Both real time model predictions and monitoring data are being combined into one online platform to provide accurate, information-rich support to wastewater network management. This platform allows for selected nodes (namely sensitive locations prone to CSO or flood events and locations where flow meters are installed) to display and present time series predictions regarding hydraulic and quality parameters. It is considered an important management tool for the operation of pumping stations and the WWTP, allowing for a more cost efficient control and contributing to the reduction of CSO and flooding impacts.

\section{Results}

Results for simulations carried out for two wet weather events regarding wastewater flow in the sewer network and WWTP system and their comparison to measured data can be seen in Figure 5.

PLS models A and B results compared to measured values of TSS and COD are presented in Figure 6 (Brito) and indicate good accuracy in predicting such water quality parameters, as referred in 3.4. Model $\mathrm{C}$ estimates also reveal the suitability of in line UV-Vis spectra as a tool to provide real time information.

Online data from the UV-Vis spectrophotometer quality station located at the WWTP entry point is already available online, allowing for accurate analysis prior to its inclusion in the global platform (Figure 7).

\section{Conclusions and future work}

The integrated system presented herein shows the ability of coupled models to represent the main spatial and temporal patterns of hydraulic and water quality in sewers and receiving water bodies. Integrated models effectively predict the system response to events and estimate discharged volumes and average pollution loads.

Furthermore, the overall results strongly indicate UV-Vis spectra may be reliable for TSS and COD estimation in urban drainage systems. Wastewater quality prediction models for the sewer system and WWTP will be further developed and tested with additional field data. The estuary model will be fully coupled with the SWMM model at all relevant outfalls prior to its inclusion in the platform. 

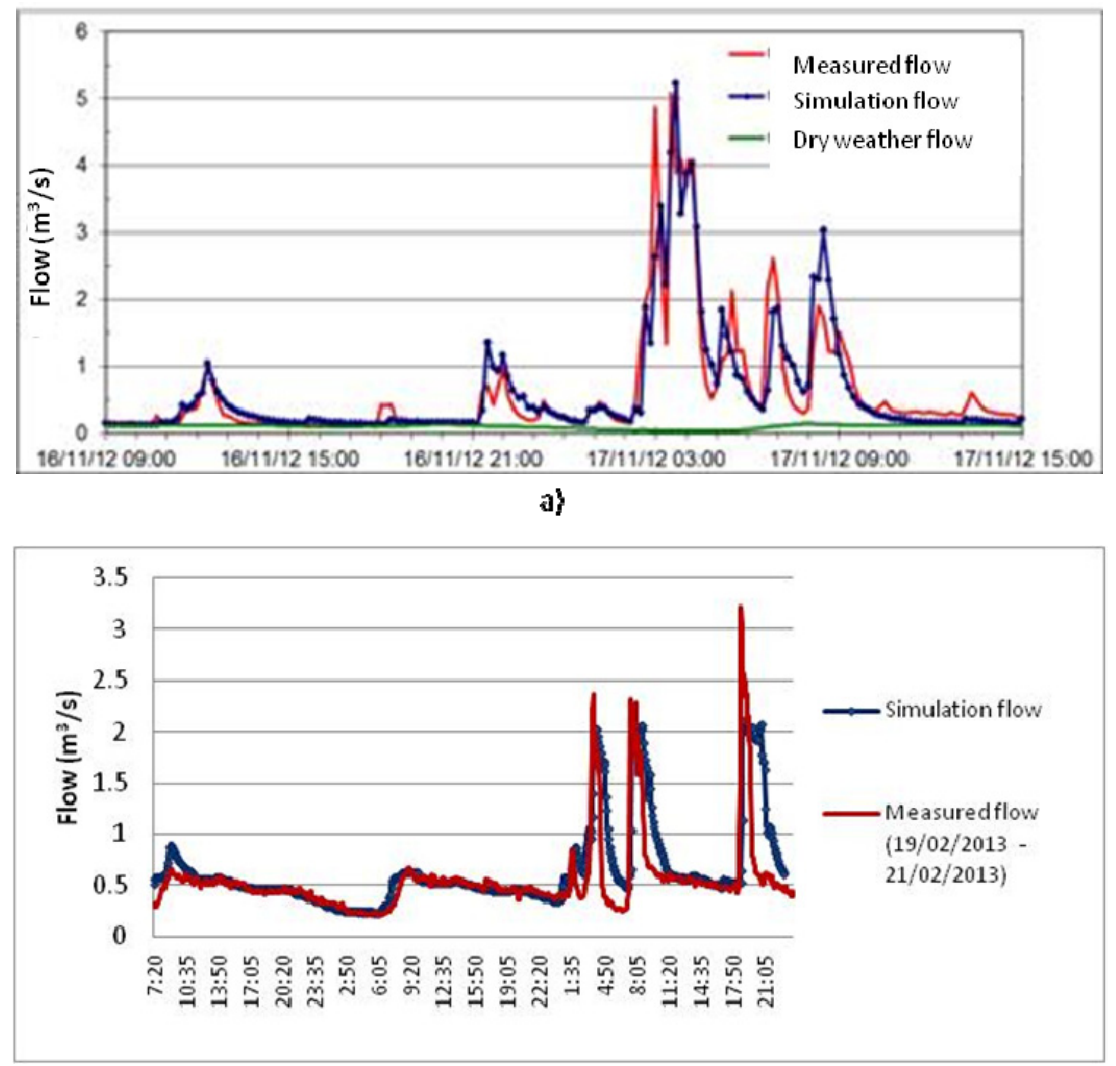

b)

Figure 5: $\quad$ Simulated and measured flows for two locations; a) uptown gravity network and b) lower riverfront point (at Terreiro do Paço).
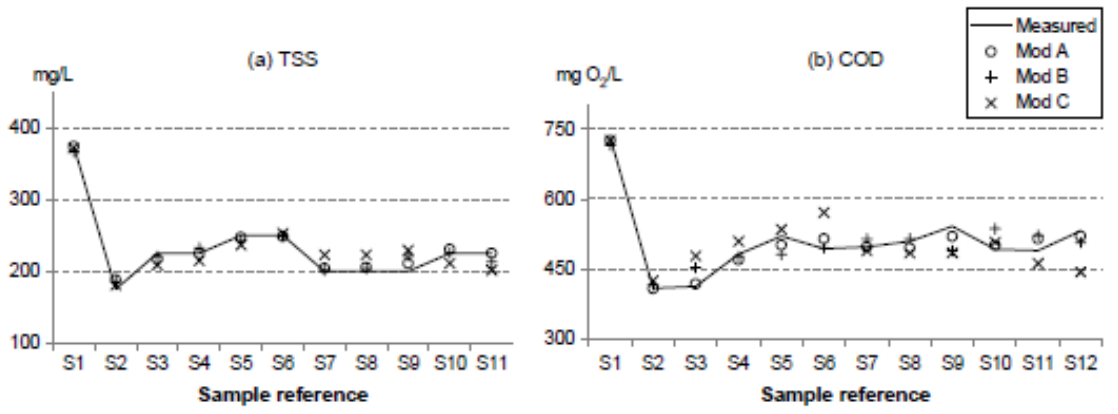

Figure 6: $\quad$ TSS and COD measured and estimated values for a selected site. 


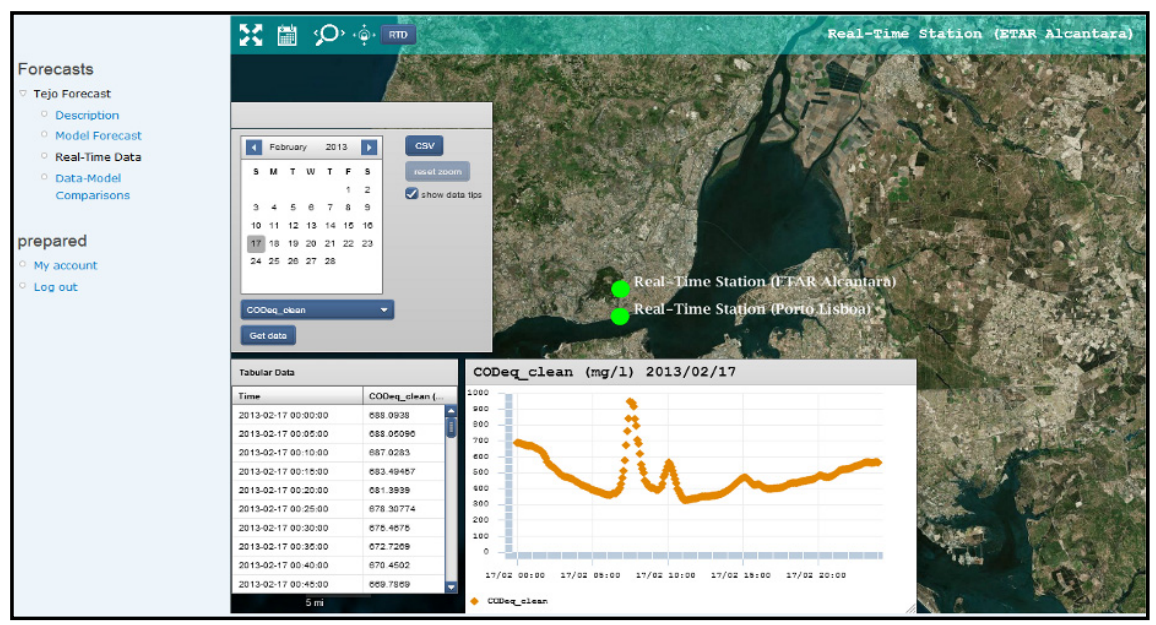

Figure 7: Real time data access interface.

\section{Acknowledgements}

This work was co-funded by: FP7, project PREPARED (FP7-ENV-2009-1 Grant agreement 244234); QREN, through Fundo Europeu de Desenvolvimento Regional (FEDER), in the scope of COMPETE - Programa Operacional Factores de Competitividade, project SI-GeA (Project n.23053); and through project SIMAI (PTDC/AAC-AMB/102634/2008). The sixth and seventh authors were co-funded by Fundação para a Ciência e Tecnologia grants SFRH/BPD/87512/2012 and SFRH/BD/82489/2011.

\section{References}

[1] Goonetilleke, A., Thomas, E., Ginn, S., \& Gilbert, D. (2005). Understanding the role of land use in urban stormwater quality management. Journal of environmental management, 74(1), 31-425.

[2] Fotopoulos, F., Makropoulos, C., \& Mimikou, M. (2010). Flood forecasting in transboundary catchments using the Open Modeling Interface . Environmental Modelling \& Software, 25(12), 1640-1649.

[3] Falconer, R., Cobby, D., Smyth, P., Astle, G., Dent, J., \& Golding, B. (2009). Pluvial flooding: new approaches in flood warning, mapping and risk management. Journal of Flood Risk Management, 2(3), 198-208.

[4] Borga, M., Anagnostou, E., Blaschl, G., \& Creutin, J.-D. (2011). Flash flood forecasting, warning and risk management: the HYDRATE project. Environmental Science \& Policy, 14(7), 834-844.

[5] Alfieri, L., Smith, P. J., Thielen-del Pozo, J., \& Beven, K. J. (2011). A staggered approach to flash flood forecasting - a case study in the Cavennes region. Advances in Geosciences, 29, 13-20. 
[6] Parker, D., Priest, S., \& McCarthy, S. (2011). Surface water flood warnings requirements and potential in England and Wales. Applied Geography, 31(3), 891-900.

[7] David, L.M., Oliveira, A., Rodrigues M., Jesus, G., Póvoa, P., David, C., Costa R., Fortunato, A., Menaia, J., Frazão, M., Matos, R. "Development of an integrated system for early warning of recreational waters contamination." Novatech. 2013.

[8] R. Salgado Brito, H.M. Pinheiro, F. Ferreira, J. Saldanha Matos \& N.D. Lourenço. "In situ UV-Vis spectroscopy to estimate COD and TSS in wastewater drainage systems." Urban Water Journal, 2013: DOI:10.1080/1573062X.2013.783087.

[9] Rossman, L.A. Stormwater Management Model User's Manual, Version 5.0 US Environmental Research Agency. EPA/600/R-05/040, 2007.

[10] M. Rodrigues, J. Costa, G.Jesus, A.B. Fortunato, J. Rogeiro, J. Gomes, A. Oliveira and L.M. David. "Application of an estuarine and coastal nowcast-forecast information system to the Tagus estuary." 6th SCACR International Short Course/Conference on Applied Coastal Research. 2013.

[11] Jesus, G., Gomes, J., Ribeiro, N.A., Oliveira, A. "Custom deployment of a Nowcast-forecast information system in coastal regions." Proceedings of Geomundus 2012.

[12] Ashley, R., Bertrand-Krajewski, J., Hvitved-Jacobsen T., Verbanck M. Solids in Sewers: Characteristics, Effects and Control of Sewer Solids and Associated Pollutants. Scientific and Technical Report No.14, IWA Publishing, 2004. 